\section{Cureus}

Received 09/19/2018

Review began 09/23/2018

Review ended 09/23/2018

Published 10/01/2018

(c) Copyright 2018

Zahirul Islam et al. This is an open access article distributed under the terms of the Creative Commons Attribution License CC-BY 3.0., which permits unrestricted use, distribution, and reproduction in any medium, provided the original author and source are credited.

\title{
Correlates of Climate Variability and Dengue Fever in Two Metropolitan Cities in Bangladesh
}

Mohammad Zahirul Islam ${ }^{1}$, Shannon Rutherford ${ }^{2}$, Dung Phung ${ }^{2}$, Md. Nazim Uzzaman ${ }^{3}$, Scott Baum ${ }^{4}$, M. Mamun Huda ${ }^{5}$, Muhammad Asaduzzaman ${ }^{6}$, Mohammad Radwanur Rahman Talukder ${ }^{7}$, Cordia Chu ${ }^{2}$

1. Centre for Environment and Population Health, School of Medicine, Griffith University, Brisbane, AUS 2. Epidemiology and Public Health, Griffith University, Brisbane, AUS 3. Epidemiology and Public Health, International Centre for Diarrhoeal Disease Research, Dhaka, BGD 4. Miscellaneous, Griffith University, Brisbane, AUS 5. Epidemiology and Public Health, University of Queensland, Brisbane, AUS 6.

Epidemiology and Public Health, International Center for Diarrhoeal Disease Research, Dhaka, BGD 7. Epidemiology and Public Health, Baker Heart and Diabetes Institute, Alice Springs, AUS

$\square$ Corresponding author: Mohammad Zahirul Islam,dr.zahirulbd@gmail.com Disclosures can be found in Additional Information at the end of the article

\section{Abstract}

Dengue fever is a major public health concern in Bangladesh with increased incidence during monsoon. We aimed to assess the correlation of temperature, humidity, and rainfall on dengue fever in two dengue endemic cities in Bangladesh. It was a time series analysis of climate factors and dengue occurrence data in Dhaka and Chittagong cities from 1 January 2000 to 31 December 2009. Daily mean temperature, rainfall, and humidity data were obtained from the Bangladesh meteorological department and daily dengue cases data were obtained from the directorate general of health services (DGHS) of Bangladesh. The mean dengue incidence was 31.62 (SD 28.7) per 100,000 in Dhaka whereas it was 5.76 (SD 11.7) per 100,000 population in Chittagong. The incidence of dengue cases was found significantly associated with the monthly mean temperature, total rainfall, and mean humidity in Dhaka, though in Chittagong, the significantly associated factors were monthly total rainfall and mean humidity. The autoregressive integrated moving average (ARIMA) model identified monthly mean humidity and total rainfall as the most significant contributing factors for dengue cases in Dhaka and Chittagong, respectively. Our study reinforces the relationship of climate parameters with dengue fever, which will support policy-makers in developing a climate-based early warning system for dengue in Bangladesh.

Categories: Environmental Health, Epidemiology/Public Health

Keywords: dengue, climate variability, bangladesh, time series analysis, tropical disease

\section{Introduction}

The global occurrence of dengue has increased radically in recent decades, endangering about half of the world's population at risk [1]. Approximately 96 million people are clinically manifested by dengue infections per year worldwide and mostly found in urban and semi-urban areas in tropical and sub-tropical climates [2]. Dengue is a climate-responsive disease and climate factors like temperature and rainfall are the most important factors in the occurrence and transmission of dengue fever [3]. Bangladesh is in the South-East Asia region of WHO, which is characterized by strong seasonal variation and heavy monsoon rainfall [4]. Dengue is highly seasonal in Bangladesh with an increased incidence during the monsoon [5]. Although the first recognized outbreak of dengue in Dhaka, the capital city of Bangladesh, was recorded in 1964 [6], followed by sporadic cases of dengue fever during 1977-78 and 1996-1997 [7-8], the 
extent of dengue occurrence in Bangladesh was poorly documented. The first identified epidemic of dengue fever in Bangladesh took place during the monsoon season of 2000 and resulted in 5,521 officially reported cases, with 93 fatalities [9-10]. From 2000-2009, 91\% of all reported dengue cases were from Dhaka, making it the most endemic urban area of the country [11]. However, dengue is also spreading to other urban cities in Bangladesh. Several studies have been conducted to see the climatic variability and spread of dengue cases in Dhaka city [12-14], but very little attention has been given in other cities in Bangladesh. Therefore, we aimed to conduct a study on climatic variability and its association with the distribution of dengue cases in not only Dhaka city but also in other urban cities in Bangladesh. Chittagong is the second largest urban city on the southeastern coast of Bangladesh, which is also endemic for dengue [15]. To our knowledge, this is the first study that aims to assess the correlation of temperature, humidity, and rainfall on dengue fever in two major urban cities (Dhaka and Chittagong) in Bangladesh.

\section{Materials And Methods}

The study was conducted in Dhaka and Chittagong cities of Bangladesh. Dhaka is the capital and the largest city of Bangladesh. It has a hot and humid tropical climate with an annual average mean temperature of approximately $26.1^{\circ} \mathrm{C}$ [16], which is optimal for the development, longevity, and fecundity of Aedes aegypti mosquito [17]. Rainfall is highly seasonal and occurs from May to September, and nearly $80 \%$ of the annual average total rainfall of $170 \mathrm{~mm}$ falls during the monsoon. The annual average mean relative humidity of Dhaka is 65.1\% [18]. Dhaka has been the site of dengue outbreaks, and it represents an ideal place for considering the impact of climate variability in relation to dengue fever [5]. Chittagong city is bounded to the east by hills merging with the sea to the west. The annual average mean temperature and total rainfall are $25.9^{\circ} \mathrm{C}$ and $249 \mathrm{~mm}$, respectively [19]. The warm and wet season starts from April and continues up to October during which mosquito-borne diseases increase significantly. The annual average mean relative humidity is recorded as $73.2 \%$, which helps the parasite to complete the necessary life cycle to transmit the infection [20]. Outbreaks of dengue fever in the last few years in this urban area [15] is the key reason to choose this area as a study site.

It was a time series analysis of climate parameters and dengue occurrence data from January 1, 2000, to December 31, 2009, in two urban cities in Bangladesh.

The daily average maximum and minimum temperatures, average rainfall, and relative humidity data were obtained from the Bangladesh meteorological department over a period of 10 years (2000-2009) for both Dhaka and Chittagong cities. Daily dengue fever data were obtained from the directorate general of health services (DGHS) of the ministry of health and family welfare (MOH\&FW) for the same duration. The total number of dengue fever cases was 22,970 during the study period of which 21,748 and 1,222 were in Dhaka and Chittagong, respectively.

All hospitals of those two cities, which were mostly government hospitals, sent their monthly dengue case report as suspected or probable dengue fever (DF) to the DGHS office. Suspected cases were those who had clinical features only and probable cases were those who had positive serological test along with clinical features. No confirmatory procedure was followed in the case detection stage although virus isolation was the confirmatory test. This study included both primary and secondary dengue infection. The physicians in each hospital diagnosed dengue fever from those patients who were admitted with acute febrile illness following a clinical case definition of dengue fever, as mentioned in the WHO guideline for dengue fever [21].

The study was approved by the research ethics committee of Griffith University, Australia. The dengue fever cases were de-identified to maintain privacy.

Means and standard deviations of monthly climatic data were calculated and compared for both 
study sites. The differences in mean temperature, mean humidity, and total rainfall between the cities were examined using a nonparametric Mann Whitney U-test. A time series plot was used to show the trends in the annual average mean temperature, mean humidity, and total rainfall for the period 2000 to 2009 . The Spearman correlation coefficient was used to examine the relationship between dengue cases and each of the climatic variables - rainfall, temperature, and humidity per month. The autoregressive integrated moving average (ARIMA) regression model was used to examine the independent relationship between dengue cases and each climatic variable per month. The dependent variable for the ARIMA model was dengue cases per month whereas the independent variables were mean monthly temperature, mean monthly humidity, and total monthly rainfall. The expert modeler available in SPSS statistical software (version 17) (SPSS Inc., Chicago, IL, USA) was used to determine the best-fitting ARIMA model for Dhaka and Chittagong cities. The stationary R-squared and Ljung Box Q tests were examined and reported to show the goodness of fit of the best-fitting ARIMA model. A p-value less than 0.05 was considered statistically significant. Data were analyzed using SPSS software version 17.

\section{Results}

\section{Trends of climate variables}

A similar increasing trend of annual average mean temperature was observed for both the cities, with a peak in 2006. The mean temperature rose by $0.7^{\circ} \mathrm{C}$ in Dhaka and $0.6^{\circ} \mathrm{C}$ in Chittagong over the period 2000 to 2009 . The lowest mean temperature in Dhaka was recorded as $25.7^{\circ} \mathrm{C}$ in the years 2000, 2003, and 2007 and $25.6^{\circ} \mathrm{C}$ in Chittagong in the year 2000 (Figure 1).
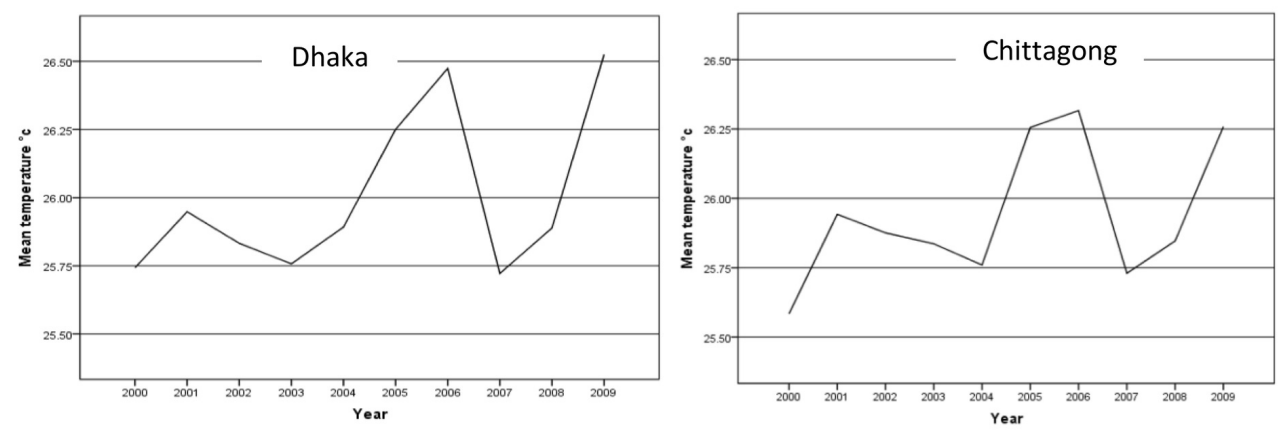

\section{FIGURE 1: Annual average mean temperature in Dhaka and Chittagong city from 2000 to 2009}

The annual average total rainfall was higher in Chittagong as compared to Dhaka. The average total rainfall in Dhaka was 150-200 mm till 2004 but became more variable for the rest of the study period. The highest rainfall of $250 \mathrm{~mm}$ in Dhaka was recorded in the year 2007. On the other hand, the average total rainfall in Chittagong was 200-300 mm from 2002 to 2006 but observed many variations during other years. The highest rainfall of $350 \mathrm{~mm}$ in Chittagong was recorded in the year 2007 (Figure 2). 


\section{Cureus}
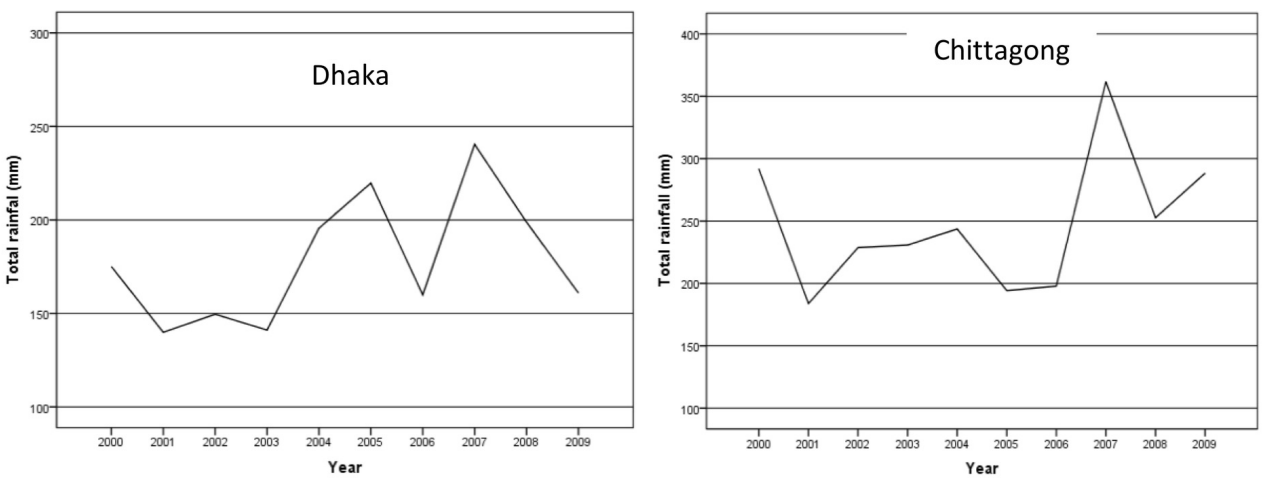

FIGURE 2: Annual average total rainfall in Dhaka and Chittagong city from 2000 to 2009

The annual average mean humidity in Chittagong was higher than in Dhaka. The mean humidity was between $72 \%$ and $76 \%$ in Dhaka except in 2009 while in Chittagong, it was around $80 \%$ except in 2002 (Figure 3).
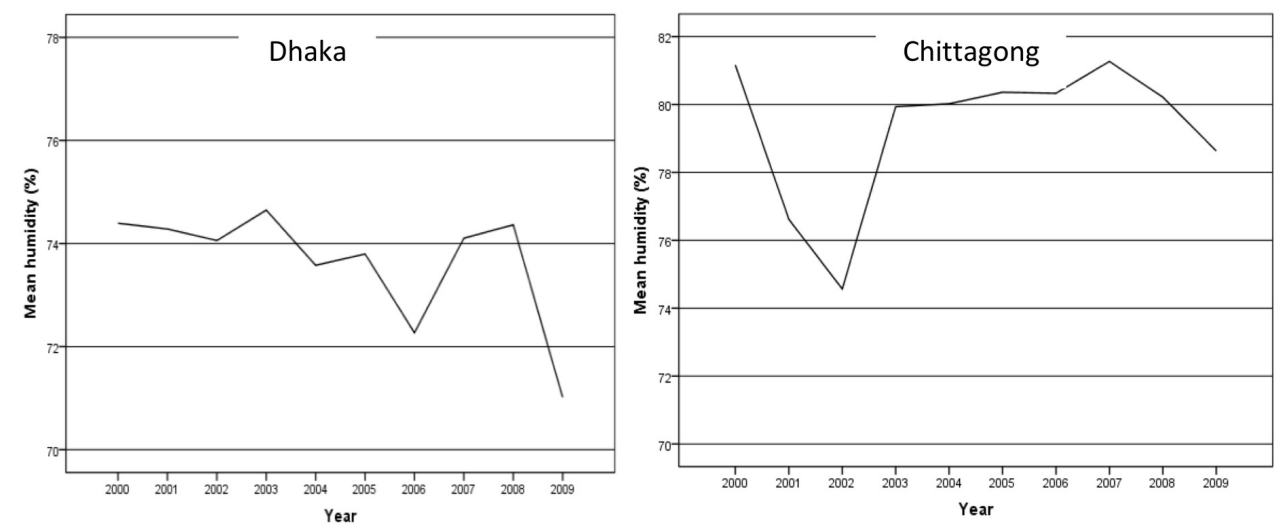

FIGURE 3: Annual average mean humidity in Dhaka and Chittagong city from 2000 to 2009

There was no statistically significant difference in terms of the mean temperature between Dhaka and Chittagong. However, the total rainfall and mean humidity were found statistically significant between the cities whereas the Spearman correlation analysis showed that in Dhaka, dengue cases were statistically significantly (P-value $<0.05$ ) associated with all the key climate variables (temperature, rainfall, and humidity) whereas in Chittagong, rainfall and humidity were statistically significantly associated (Table 1 ). 


\section{Cureus}

\begin{tabular}{|c|c|c|c|c|c|}
\hline \multirow[t]{2}{*}{ Climate variables } & Dhaka & Chittagong & P-value & Dhaka & Chittagong \\
\hline & Mean (SD) & Mean (SD) & & $r(P)$ & $r(P)$ \\
\hline Temperature in ${ }^{\circ} \mathrm{C}$ & $26.0(0.30)$ & $25.9(0.25)$ & 0.762 & $0.300(0.001)$ & $0.137(<0.135)$ \\
\hline Rainfall in mm & $178.1(34.4)$ & $247.38(54.5)$ & 0.005 & $0.356(<0.0001)$ & $0.307(0.001)$ \\
\hline Humidity in \% & $73.65(1.14)$ & $79.31(2.14)$ & $<0.0001$ & $0.574(<0.0001)$ & $0.409(<0.0001)$ \\
\hline
\end{tabular}

TABLE 1: Comparison and correlation between dengue cases and climate variables of Dhaka and Chittagong from 2000 to 2009

$r=$ correlation coefficient

\section{Trends of dengue fever}

The annual incidence of dengue cases varied substantially between the two cites. The mean dengue incidence was 31.62 (SD 28.7) per 100,000 in Dhaka whereas the mean dengue incidence in Chittagong was 5.76 (SD 11.7) per 100,000 population. The incidence in Chittagong was lower than in Dhaka. The numbers and rates of dengue cases varied significantly from year to year in Dhaka and have decreased gradually, whereas in Chittagong rates have been consistently low since 2001 (Figure 4).
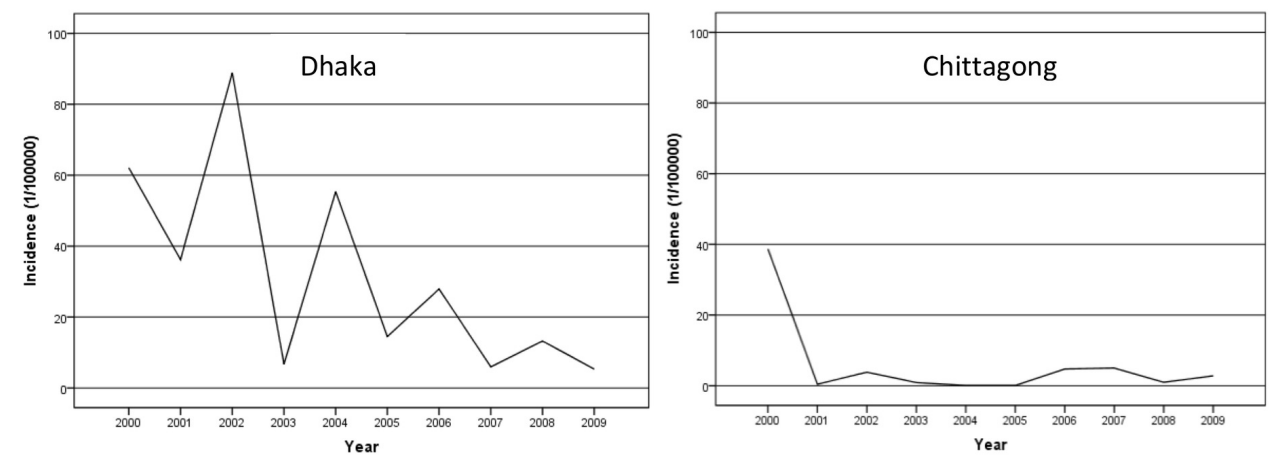

FIGURE 4: Annual incidence of dengue cases in Dhaka and Chittagong city from 2000 to 2009

In 2002, the highest number of dengue cases reached more than 3,000 in Dhaka whereas in Chittagong, it was around 400 in the year 2000 (Figure 5). 


\section{Cureus}
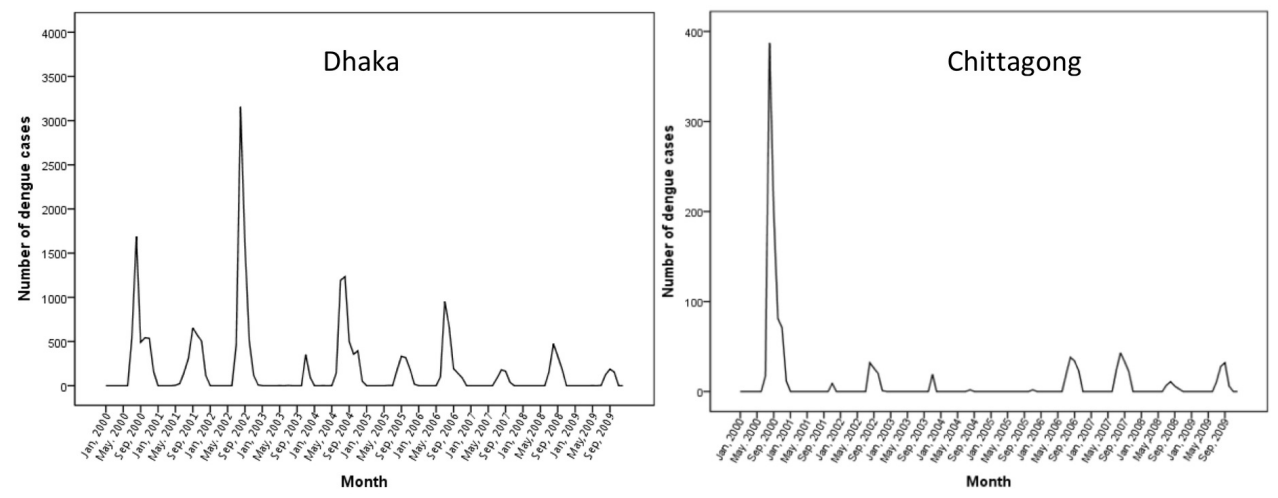

FIGURE 5: Monthly distribution of dengue cases in Dhaka and Chittagong city from 2000 to 2009

The autoregressive integrated moving average (ARIMA) model demonstrated that the monthly average dengue cases were significantly associated with the mean monthly humidity in Dhaka up to three-months lags. The association was positive at lag $0(\mathrm{P}<0.001)$ and $1(\mathrm{P}<0.001)$ month lag, but it was negative at two months lag $(\mathrm{P}<0.001)$ and for Chittagong, the model showed that the monthly total rainfall was significantly $(\mathrm{P}$-value $<0.05)$ associated with monthly dengue cases at the 0 month lag only (Table 2).

\begin{tabular}{|c|c|c|c|c|c|c|}
\hline City & Climate variable & Lag (month) & Estimate (SE) & P-value & Stationary R-squared & Ljung Box Q (18) \\
\hline \multirow[t]{3}{*}{ Dhaka } & Mean humidity & Lag 0 (month) & $5.697(0.877)$ & $<0.001$ & & \\
\hline & & Lag 1 (month) & $1.276(0.053)$ & $<0.001$ & 0.935 & 0.74 \\
\hline & & Lag 2 (month) & $-0.866(0.051)$ & $<0.001$ & & \\
\hline Chittagong & Total rainfall & Lag 0 (month) & $0.004(0.002)$ & 0.023 & 0.984 & 0.562 \\
\hline
\end{tabular}

TABLE 2: The autoregressive integrated moving average (ARIMA) model parameters

\section{Discussion}

This study provides some evidence of the climate-sensitivity of dengue fever outbreaks and the vulnerability to the health consequences of climate change in Bangladesh. It has been identified that dengue rates co-vary with climatic patterns [22], however, the relation between climatic patterns and dengue fever is not well understood [23]. This is because of the complexity of the life cycle of the vector and the host. The life cycle, maturation, and breeding pattern of the Aedes aegypti vector is clearly climate sensitive, and is also influenced by a range of meteorological or related factors, not just the three common features of "weather," but also relative humidity, solar radiation, wind direction and speed, ocean temperatures, and some other factors, eg, environment, waste, etc. [24]. However, from the point of view of the current study, the main shortfall is the lack of insight into the status of the climate-dengue link in the context of Bangladesh. A thorough literature review was carried out on climate change and the transmission of vector-borne diseases, including dengue variants with their inclusion criteria. 
Very few studies were found in this regard [25], although Bangladesh has all the favorable conditions for dengue to thrive. Since that review, there have been at least two studies identified that partly addressed this gap. The seasonal autoregressive integrated moving average (SARIMA) models for Dhaka did not take account of climate variables per se, but instead seasonality, which, naturally, inherently captures key climatic variables [26]. In another study in Bangladesh, a model that includes a range of climatic factors (monthly humidity, rainfall, and minimum and maximum temperature) was built and found that climatic factors, in particular, rainfall, temperature, and relative humidity did significantly predict monthly dengue occurrence [7]. Furthermore, the seasonality of dengue cases and the seasonality of rainfall and temperature were found largely consistent across the years in Dhaka city [13]. Our study found that the mean monthly rainfall and humidity were statistically significant for both the cities but the monthly mean temperature was significant only for Dhaka.

Moreover, this study attempts to look into the climate parameters of dengue in the large cities for a decade. But, the lack of data or the poor record-keeping system of different strata of population vulnerability (eg. gender differences, age difference, socio-economic difference, rural versus urban, etc.) are a key gap. The irregular or poor quality data affected the extent and comprehensiveness of the analysis of dengue data for Chittagong and Dhaka too. There were more missing data or incomplete data in Chittagong than in Dhaka, which indicates a poor data record-keeping and reporting system in Chittagong. It may be due to a weak monitoring system or a lack of awareness among the reporting authorities.

\section{Conclusions}

This study reinforces the relationship of climate variability with dengue fever in two big cities, Dhaka and Chittagong, in Bangladesh. The annual average rainfall and humidity were significantly associated with dengue occurrence in both cities whereas annual average temperature was found significant factor only in Dhaka. The study findings will be helpful for policy-makers and practitioners to develop a climate-based dengue early warning systems in Bangladesh. Furthermore, this study recommends community-based surveillance for developing an effective dengue prevention strategy in the dengue endemic cities in Bangladesh.

\section{Additional Information}

\section{Disclosures}

Human subjects: All authors have confirmed that this study did not involve human participants or tissue. Animal subjects: All authors have confirmed that this study did not involve animal subjects or tissue. Conflicts of interest: In compliance with the ICMJE uniform disclosure form, all authors declare the following: Payment/services info: All authors have declared that no financial support was received from any organization for the submitted work. Financial relationships: All authors have declared that they have no financial relationships at present or within the previous three years with any organizations that might have an interest in the submitted work. Other relationships: All authors have declared that there are no other relationships or activities that could appear to have influenced the submitted work.

\section{Acknowledgements}

We gratefully acknowledge the support of Griffith University postgraduate scholarships for this study. We would like to express our sincere thanks to the Bangladesh meteorological department and the directorate general of health services (DGHS) of Bangladesh for providing data.

\section{References}

1. Dengue and severe dengue. (2018). Accessed: September 17, 2018:

http://www.who.int/en/news-room/fact-sheets/detail/dengue-and-severe-dengue. 
2. Bhatt S, Gething PW, Brady OJ, et al.: The global distribution and burden of dengue . Nature. 2013, 496:504-507. 10.1038/nature12060

3. Naish S, Dale P, Mackenzie JS, McBride J, Mengersen K, Tong S: Climate change and dengue: a critical and systematic review of quantitative modelling approaches. BMC Infect Dis. 2014, 14:167. 10.1186/1471-2334-14-167

4. WHO regional office for South-East Asia: Comprehensive guidelines for prevention and control of dengue and dengue haemorrhagic fever. 2011, Accessed: September 17, 2018: http://apps.searo.who.int/pds_docs/B4751.pdf?ua=1.

5. Sharmin S, Glass K, Viennet E, Harley D: Interaction of mean temperature and daily fluctuation influences dengue incidence in Dhaka, Bangladesh. PLoS Negl Trop Dis. 2015, 9:e0003901. 10.1371/journal.pntd.0003901

6. Russell PK, Buescher EL, McCown JM, Ordoñez J: Recovery of dengue viruses from patients during epidemics in Puerto Rico and East Pakistan. Am J Trop Med Hyg. 1966, 15:573-579. 10.4269/ajtmh.1966.15.573

7. Karim MN, Munshi SU, Anwar N, Alam MS: Climatic factors influencing dengue cases in Dhaka city: a model for dengue prediction. Indian J Med Res. 2012, 136:32-39.

8. Amin MMM, Hussain AMZ, Nahar K, Chowdhury IA, Murshed M, Chowdhury SA: Serodiagnosis of dengue infections in four metropolitan cities of Bangladesh. Dengue Bulletin. 2000, 24:29-33. Accessed: September 17, 2018: https://pdfs.semanticscholar.org/be5b/78b6b2cc375f9a4a87a4cfd229b5faeb6344.pdf.

9. Banu S, Hu W, Hurst C, Guo Y, Islam MZ, Tong S: Space-time clusters of dengue fever in Bangladesh. Trop Med Int Health. 2012, 17:1086-1091. 10.1111/j.1365-3156.2012.03038.x

10. Chowdhury PD, Paul KK, Haque CE, et al.: Dengue seroprevalence, seroconversion and risk factors in Dhaka, Bangladesh. PLoS Negl Trop Dis. 2017, 11:e0005475.

10.1371/journal.pntd.0005475

11. Sharmin S, Viennet E, Glass K, Harley D: The emergence of dengue in Bangladesh: epidemiology, challenges and future disease risk. Trans R Soc Trop Med Hyg. 2015, 109:619627. 10.1093/trstmh/trv067

12. Sharmin S, Glass K, Viennet E, Harley D: A Bayesian approach for estimating under-reported dengue incidence with a focus on non-linear associations between climate and dengue in Dhaka, Bangladesh. Stat Methods Med Res. 2018, 27:991-1000. 10.1177/0962280216649216

13. Morales I, Salje H, Saha S, Gurley ES: Seasonal distribution and climatic correlates of dengue disease in Dhaka, Bangladesh. Am J Trop Med Hyg. 2016, 94:1359-1361. 10.4269/ajtmh.15-0846

14. Githeko AK: Advances in developing a climate based dengue outbreak models in Dhaka, Bangladesh: challenges \& opportunities. Indian J Med Res. 2012, 136:7-9.

15. Dengue fever and dengue haemorrhagic fever . (2003). Accessed: September 17, 2018: http://www.whoban.org/communicable_dis_dengue.html.

16. Weatherbase: Dhaka, Bangaldesh. (2018). Accessed: September 17, 2018: http://www.weatherbase.com/weather/weather.php3?s=32914\&cityname=Dhaka-Bangladesh.

17. Marinho RA, Beserra EB, Bezerra-Gusmão MA, Porto VS, Olinda RA, Santos CA: Effects of temperature on the life cycle, expansion, and dispersion of Aedes aegypti (Diptera: Culicidae) in three cities in Paraiba, Brazil. J Vector Ecol. 2016, 41:1-10. 10.1111/jvec.12187

18. District statistics 2011. (2013). Accessed: September 17, 2018: http://203.112.218.65:8008/WebTestApplication/userfiles/Image/District\%20Statistics/Dhaka.pdf

19. Weatherbase: Chittagong, Bangladesh. (2018). Accessed: September 17, 2018: http://www.weatherbase.com/weather/weather.php3?s=87914\&cityname=ChittagongBangladesh.

20. Patz JA, Martens WJ, Focks DA, Jetten TH: Dengue fever epidemic potential as projected by general circulation models of global climate change. Environ Health Perspect. 1998, 106:147153. 10.1289/ehp.98106147

21. DGHS and WHO Bangladesh: National guidelines for clinical management of dengue syndrome . 2000, Accessed: September 17, 2018: http://www.sdnbd.org/sdi/issues/health/dengue/other/dng.PDF.

22. Reiter P: Weather, vector biology, and arboviral recrudescence . The Arboviruses: Epidemiology and Ecology. Monath TP (ed): CRC Press, Florida; 1988. 1:245-255.

23. Gubler DJ, Reiter P, Ebi KL, Yap W, Nasci R, Patz JA: Climate variability and change in the United States: potential impacts on vector- and rodent-borne diseases. Environ Health Perspect. 2001, 109:223-233. 10.1289/ehp.109-1240669

24. Institute of Medicine: Vector-Borne Diseases: Understanding the Environmental, Human 


\section{Cureus}

Health, and Ecological Connections, Workshop Summary. The National Academies Press, Washington DC; 2008. 10.17226/11950

25. Zhang Y, Bi P, Hiller JE: Climate change and the transmission of vector-borne diseases: a review. Asia Pac J Public Health. 2008, 20:64-76. 10.1177/1010539507308385

26. Choudhury MZ, Banu S, Islam MA: Forecasting dengue incidence in Dhaka, Bangladesh: a time series analysis. Dengue Bulletin. 2008, 32:29-37. Accessed: September 17, 2018: http://apps.who.int/iris/bitstream/handle/10665/170465/db2008v32p29.pdf? sequence $=1$ \&isAllowed $=y$. 